\title{
HIMAWARI-8 GEOSTATIONARY SATELLITE OBSERVATION OF THE INTERNAL SOLITARY WAVES IN THE SOUTH CHINA SEA
}

\author{
Qidong Gao ${ }^{1,2}$, Di Dong ${ }^{3}$, Xiaofeng Yang ${ }^{1,}$ *, Letu Husi ${ }^{1}$, Huazhe Shang ${ }^{1}$ \\ ${ }^{1}$ State Key Laboratory of Remote Sensing Science, Institute of Remote Sensing and Digital Earth, Chinese Academy of Sciences, \\ 100101, Beijing, China -(gaoqd, yangxf, husiletu, shanghz)@ radi.ac.cn \\ ${ }^{2}$ University of Chinsese Academy of Sciences, 100049, Beijing, China; \\ ${ }^{3}$ South China Sea Institute of Planning and Environmental Rsearch,SOA, 510320, Guangzhou, China -dongdide90@126.com
}

\section{Commission VI, WG VI/4}

KEY WORDS: Himawari-8, Advanced Himawari Imager, Internal Solitary Waves, South China Sea

\begin{abstract}
:
The new generation geostationary meteorological satellite, Himawari-8 (H-8), was launched in 2015. Its main payload, the Advanced Himawari Imager (AHI), can observe the earth with 10-minute interval and as high as $500 \mathrm{~m}$ spatial resolution. This makes the H-8 satellite an ideal data source for marine and atmospheric phenomena monitoring. In this study, the propagation of internal solitary waves (ISWs) in the South China Sea is investigated using AHI imagery time series for the first time. Three ISWs cases were studied at 3:30 8:00 UTC on 30 May, 2016. In all, 28 ISWs were detected and tracked between the time series image pairs. The propagation direction and phase speeds of these ISWs are calculated and analyzed. The observation results show that the properties of ISW propagation not stable and maintains nonlinear during its lifetime. The resultant ISW speeds agree well with the theoretical values estimated from the Taylor-Goldstein equation using Argo dataset. This study has demonstrated that the new generation geostationary satellite can be a useful tool to monitor and investigate the oceanic internal waves.
\end{abstract}

\section{INTRODUCTION}

The oceans are continuously stratified due to vertical variations in the temperature and salinity fields. Internal solitary waves (ISWs) are ubiquitous in stratified oceans of continental shelves and marginal seas( $\mathrm{Li}$ et al., 2000). ISWs can cause large isopycnal displacements and strong vertical and horizontal currents in the ocean, which constitute potential threats to manmade structures of marine engineering operations, such as drilling platform and oil pipeline, and even the security of ships. Also, the turbulent mixing caused by their breaking plays a significant role in the distribution of nutrients, which may also affect primary production and the development of marine fisheries. As a marginal sea part of the Pacific Ocean, the South China Sea (SCS) has been a hot spot for the research of internal solitary waves (ISWs) for decades (shown in Figure 1)(Dong et al., 2016; Duda et al., 2004; Hsu et al., 2000; Lien et al., 2005; Liu et al., 1998b; Orr and Mignerey, 2003; Ramp et al., 2004; Zhao et al., 2004). Compared with surface waves, ISWs tend to have larger horizontal scale (up to $200 \mathrm{~km}$ ), bigger vertical amplitude (up to 200m), and lower frequency. These largewavelength waves are difficult to monitor in a large scale with in situ or shipboard instruments. Thus remote sensing has been an important tool to observe and monitor ISWs in the ocean .

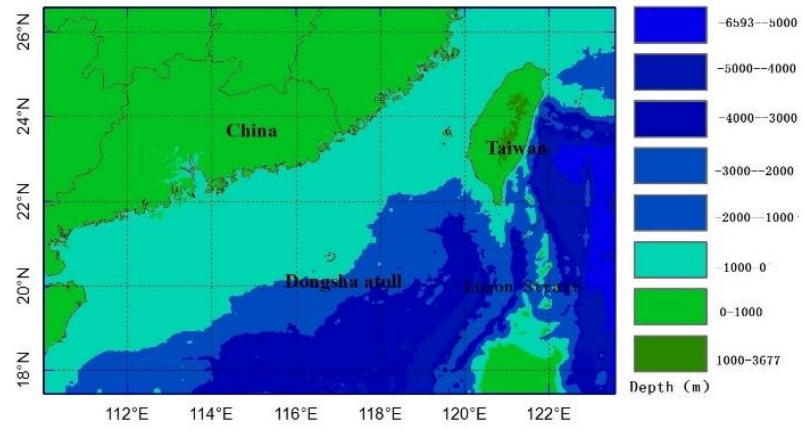

Figure 1. Bottom topographic map of the northern SCS and its adjacent sea. The intensive work for this paper research is carried out mostly in the sea area near Dongsha atoll.

With the development of satellite technology, many high-spatial resolution sensors onboard satellites have showed their ability to detect ISWs. Such sensors include the European Remote-Sensing Satellite-2(ERS-2) Synthetic Aperture Radar (SAR), the Environment Satellite (ENVISAT) Advanced SAR (ASAR) and the RADARSAT (Brandt et al., 1999; Chong et al., 2010; da Silva et al., 2009; Yang et al., 2012), the Moderate Resolution Imaging radiometer (MODIS) aboard Terra (Jackson, 2007; Liu et al., 2013). However, all the above sensors are from polar-orbit satellites, and their temporal resolutions are not high enough for the dynamic monitoring of ISWs during their lifetime. The new generation meteorological geostationary satellites, such as the

\footnotetext{
* Xiaofeng Yang (1982- ), male,Ph.D., Professor. His research interests include satellite oceanography, marine and atmospheric pollution monitoring, synthetic aperture radar image processing, and marine atmospheric boundary layer process studies.
} 
Himawari-8 satellite (Japan), GOES-R (USA) and FengYun 4 (China) etc. Which are designed mainly for weather forecasting, can be used to monitor ISWs with high temporal resolution (about several minutes) under favorable conditions. Also, images with a spatial resolution of $1 \mathrm{~km} / 0.5 \mathrm{~km}$ can be obtained for the visible band, which is sufficient to detect large-amplitude ISWs in the SCS (Zhao et al., 2014).

ISWs may travel over a distance of hundreds of kilometers, due to a balance between nonlinear and dispersive effects(Alpers, 1985; Liu et al., 1998a). ISWs propagation parameters such as displacement distance, amplitude, propagation direction and phase speed have been intensively investigated with satellite images (Liu et al., 2014b; Xue et al., 2013; Zheng et al., 2001).The propagation speed of ISWs is an important dynamic signature for understanding the ISW generation, propagation, and evolution. It is affected by several environmental factors, such as the water stratification, water depth and background current field. Researchers once used one satellite image containing two packets of ISWs to estimate the phase speed of ISWs, based on the assumption that these ISW packets are of the same origin with the time interval of one local semi-diurnal tidal period. For example, Porter and Thompson estimated the ISW phase speed with the spatial difference between the two leading wave crests in one image and assumed the time interval to be the M2 internal tide (12.42h) (Porter and Thompson, 1999). Another kind of method is based on at least one pair of two images observing the same ISW packet. As the shapes of the nonlinear ISWs may change due to the different background ocean conditions (different water depths, stratifications, etc.), the time interval of the image pair is generally not so long as one semi-diurnal tidal period in order to ensure better reliability of the assumption that the ISW packets in the two images are of the same origin (Hong et al., 2015; Liu et al., 2014a; Meng and Zhang, 2007).

In this paper, the propagation of ISWs is observed using the Advanced Himawari Imager (AHI) onboard Hamawari-8 satellite for the first time. This satellite carries significantly higher radiometric, spectral, and spatial resolution sensor than those previously available in the geostationary orbit. Thus, one ISW may be observed 2 times by the AHI in ten mins. In this study, we demonstrate that the propagation directions and phase speeds of ISWs obtained by 28 images containing three single ISW packets. The main advantage of this data source is that it can provide the near instantaneous spatial variation information of the ISW propagation, thanks to the high temporal resolution and large coverage of AHI images.

This paper is organized as follows. In section 2, we describe the AHI and MODIS images, as well as the method for estimating the ISW propagation direction and phase speed from both AHI images and theoretical simulation. In section 3, propagation directions and speeds of ISWs are presented and analyzed based on the time series of the AHI images. Section 4 is the discussion and summary parts, respectively.

\section{DATA AND METHOD}

\subsection{Satellite Images}

The Himawari-8 satellite is a new geostationary meteorological satellite operated by the Japan Meteorological Agency (JMA), which replaced the Japanese Multifunctional Transport Satellite (MTSAT-2) and became operational on 7 July 2015. The H-8 satellite has 16 observation bands, and the spatial resolution is 0.5 or $1 \mathrm{~km}$ for visible and near-infrared bands and $2 \mathrm{~km}$ for infrared bands. The H-8 geostationary satellite with shortened revisit time (around $10 \mathrm{~min}$ for Full Disk and $2.5 \mathrm{~min}$ for sectored regions), has updated levels of capacity for the identification and tracking of rapidly changing weather phenomena and the derivation of related quantitative products (BESSHO et al., 2016; Letu et al., 2014; Shang et al., 2017). In this study, the red (500m) bands are used to detect ISWs in the SCS.

The moderate-resolution imaging spectroradiometer (MODIS) is a payload scientific instrument built by Santa Barbara Remote Sensing that was launched into Earth orbit by NASA in 1999 on board the Terra (EOS AM) Satellite. The instruments obtain data in $2230 \mathrm{~km}$ swath with 36 spectral bands ranging in wavelength from $0.4 \mu \mathrm{m}$ to $14.4 \mu \mathrm{m}$ and at varying spatial resolutions (2 bands at $250 \mathrm{~m}, 5$ bands at $500 \mathrm{~m}$ and 29 bands at $1 \mathrm{~km}$ ). Two of spectral bands (Red and NIR) are widely used to detect and track ISWs (Bai et al., 2014b; Ho et al., 2009; Kao et al., 2007; Sun et al., 2014). In this study, MOD09GQ daily reflectance products at 250-m resolution are used for comparison with H-8 satellite data

Three case studies of ISWs were carried out in the SCS at 3:30 8:00 UTC (Universal Time Coordinated) on 30 May, 2016. Altogether, 28 AHI images containing three ISW packets are collected for analysis. These AHI images are selected because they clearly observed three different packets of ISWs, in the east of Dongsha atoll, north and northwest of Dongsha atoll respectively. For easy identification, we label the three ISW cases in the images alphabetically from east to west: a, b, c. ISW packets in MODIS images and AHI images are labeled with number 1 and number 2 respectively (Figure. 2).
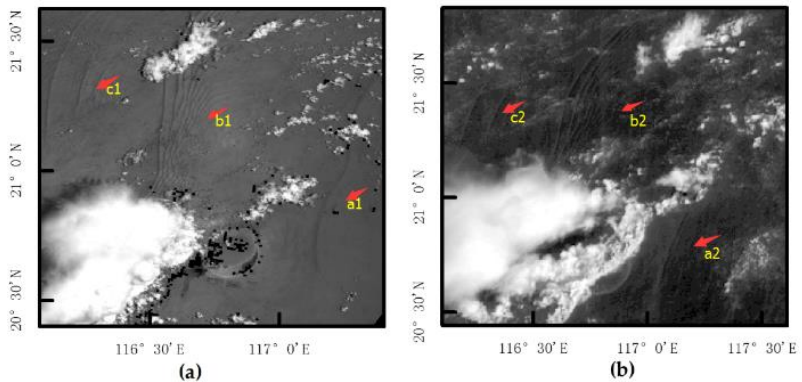

Figure 2. Three ISWs were detected by Terra and H-8 satellite at 30 May, 2016. (a) MODIS, 3:30 UTC; (b) AHI, 4:00 UTC. 
All AHI images have been calibrated and georeferenced. Three factors limit the detection or continuous tracking of ISWs in the ocean: (1) the sea surface signatures of ISWs are overlaid with clouds so it is difficult to extract the ISW wave crests; (2) the displacements of ISW wave crests is too small to differentiate in ten minutes; (3) the relative angle between the sun and the satellite is not meet the imaging mechanism of ISWs under the condition of sun glint(Bai et al., 2014a; Cox and Munk, 1954; Gagliardini, 2011; Jackson and Alpers, 2010; Shao et al., 2011; Zhang and Wang, 2010). To ensure accuracy, we abandon some degraded images mainly due to the above three factors, and resulted in 19 images observing the ISW ' $b$ ' in the north of Dongsha atoll. East and northwest of the Dongsha atoll, we found 5 images and 6 images, respectively. Locations of wave crests are obtained from the AHI images in a Geographic Information System (GIS) environment. These leading wave crests are shown in Figure 3.

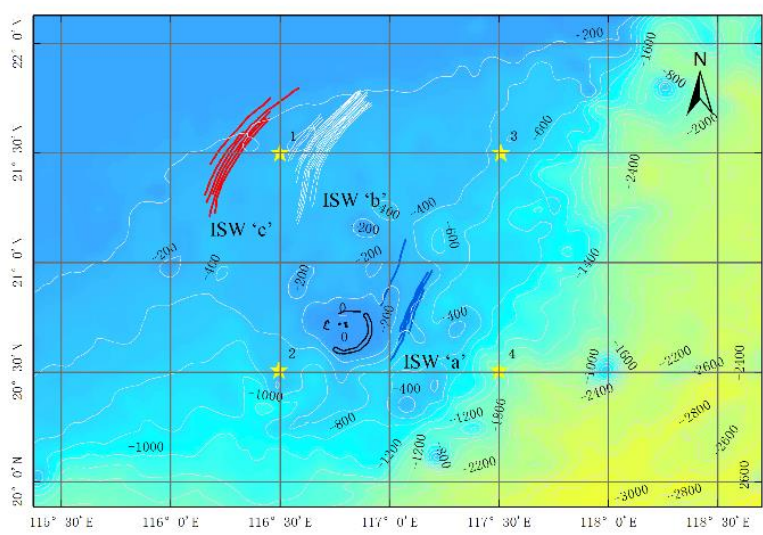

Figure 3. The H-8 satellite images near Dongsha Atoll, collected at 30, May 2016, the leading wave crests of ISW 'a', 'b' and 'c' are shown in blue, white and red respectively. The gray contours are bathymetric isobaths. Each curve represents a leading ISW wave crest imaged by the AHI instrument. The yellow stars indicates Argo's locations on May 2016, and labeled with number $1 \sim 4$.

\subsection{ISW Propagation Direction Extraction}

The ISW propagation direction is a significant parameter for studying the evolution and propagation of ISWs and it ranges between westward and northwestward in the SCS (Li et al., 2008) The propagation direction of ISW can be extracted from leading wave crests of packets.

Figure. 4(a) shows the propagation direction extraction sketch. First, draw the straight line between the two end points of the wave crest; second, get the midpoint of the straight line, and draw a transect line through the midpoint perpendicular to the connection of two end points. And the drawn transect line is parallel to the propagation direction of the ISW. The angle between the transect line and the north is the angle of the ISW propagation direction. In the Figure 4(a), curve $A B$ is the wave crest, point $C$ is the midpoint of the straight line $A B$, transect line
$\mathrm{CD}$ is perpendicular to line $\mathrm{AB}$, angle "a" is the angle between the propagation direction and North direction. For propagation direction is relatively stable during observation, we calculate partial propagation directions of each ISW case in this study. Figure 4(b) show the time series of propagation directions extracted from ISW 'c'.

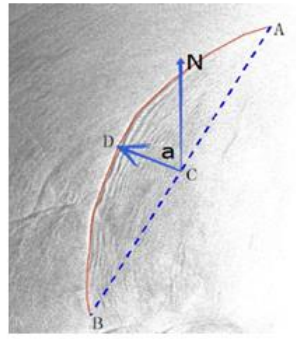

(a)

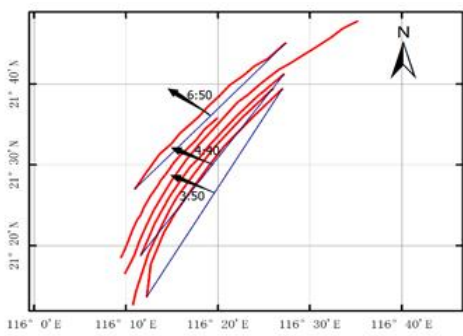

(b)
Figure 4. ISW propagation information extraction

\subsection{ISW Phase Speed Caculation}

The ISW phase speed is calculated with the displacements of wave crests in the ISW propagation direction and the corresponding imaging time interval (10 min for ideal condition). Figure 5 shows the sketch of ISW ' $b$ ' phase speed estimation. To calculate the ISW propagation speed at any position along the wave crest, we used the similar method as Liu et al.(Liu et al., 2014a) with our AHI time series images. Here we simply introduce the calculation details. We draw a line perpendicular to both ISWs from two sequential images, and measure the distance between the two intersection points (the solid red points in Figure 5) between the line and the corresponding wave crests in a GIS environment, which is denoted as $D_{\partial}$ here. Then the ISW phase speed $C_{\partial}$ can be calculated with

$$
C_{\partial}=\frac{D_{\partial}}{T}
$$

Where $T$ is the interval time of the corresponding two images observing the same ISW packet. The measurement errors can be reduced when we average the eight measurements with the neighboring points. The distance measurements of $\mathrm{T} 1 \sim \mathrm{T} 8$ are depicted in Figure 5. 


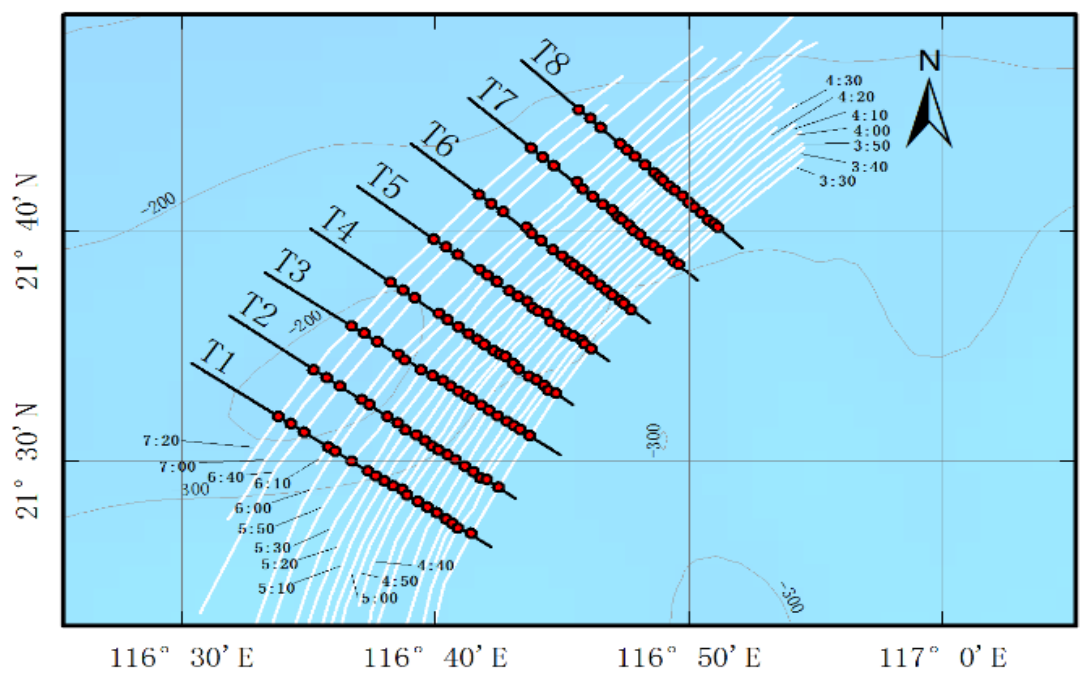

Figure 5. The intersection of the ISW ' $b$ ' propagation lines T1 T8 with wave crests. The wave crests are labeled with imaging time, the distance of two adjacent intersection points (solid red points) is ISW propagation distance.

\subsection{Theoretical Phase Speeds from the T-G Equation}

In this study, we used a stratification profile based on observations in our inversion (using Argo dateset). The vertical structure of each mode is determined by the Taylor-Goldstein equation with no background current(Gill, 1982).

$$
\begin{gathered}
\left(\frac{d^{2}}{d z^{2}}+\frac{N^{2}(z)}{C_{e}^{2}}\right) W(z)=0 \\
W(0)=W(-H)=0
\end{gathered}
$$

where $N^{2}(z)$ is the buoyancy frequency squared, $Z$ is the vertical coordinates, and $C_{\mathrm{e}}$ is the eigenspeed, and $W(Z)$ is the vertical displacement of linear waves. Assuming the internal solitary waves are of the Korteweg-deVries type of wave, the nonlinear phase speed have to be considered. The actual nonlinear phase speed depends on its amplitude.

$$
C=C_{e}+\frac{1}{3} \alpha \eta
$$

Where $\alpha$ is the nonlinear coefficient and $\eta$ is the wave amplitude. Since the amplitude is unknown, we assume it is $20 \mathrm{~m}$ in research area (depth less than $1000 \mathrm{~m})($ Orr and Mignerey, 2003), and $\alpha$ is taken as $-0.02 S^{-1}$ (Alpers, 1985).

Argo dataset were collected from global gridded NetCDF dataset produced by the Barnes Method (BOA-Argo) on May 2016 (Li Hong, 2017), indicated by the yellow star in Figure 3. The BOAArgo dataset provides monthly $1^{\circ} \times 1^{\circ}$ climatological ocean stratification profiles, includes temperature, salinity, isothermal layer depth, mixed layer depth and composed mixed layer depth.

\section{RESULTS}

Based on 28 collected AHI images collected from 3:30 to 8:00 UTC on 30 May, 2016, we analyze three ISW cases in the SCS. After abandoning the degraded images, the effective imaging times of ISW 'a', ISW 'b' and ISW 'c' are 5 times, 19 times and 6 times respectively.

\subsection{The Time Series of ISWs}

Time series of ISW 'b' propagation on 30 May, 2016 are shown in Figure 6. The sequential variations of the wave crests are visible from the AHI images. One ISW packet consists of a leading wave of the largest wavelength followed by trailing wave trains with decreasing wavelengths. The leading crest is usually the longest and brightest. From the image sequences, the main wave crests are propagating in a north-westward direction, with small wave pattern variations. In 4:00 5:00 UTC, the AHI data shows an increasingly clear wave crest, but in 5:20 7:00 UTC, the wave crests become blurred with temporal changes. This may be caused by the motion of the sun, which degrades the optical sun glint mechanism of ISWs (Cox and Munk, 1954; Jackson and Alpers, 2010; Liu et al., 2014b; Zhang and Wang, 2010). Compared with traditional optical instruments such as MODIS, AHI onboard the H-8 satellite with shortened revisit time and high temporal resolution has stronger capacity to detect or monitor ISWs in the SCS. For example, clouds are one important factor, which limits the reliable or complete imaging of ISWs. As the H-8 satellite provides images with much larger temporal resolution, it significantly increases the possibility of detecting ISWs in the SCS, compared with the traditional optical sensors onboard polar-orbit satellites. 


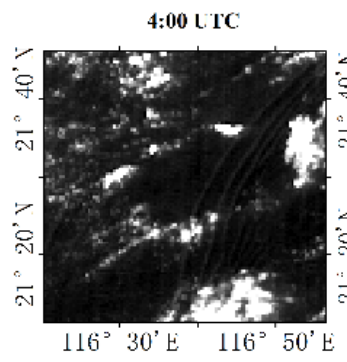

(a)

5:00 UTC

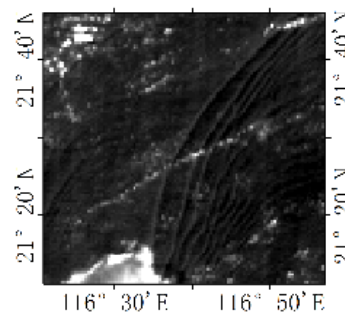

(d)

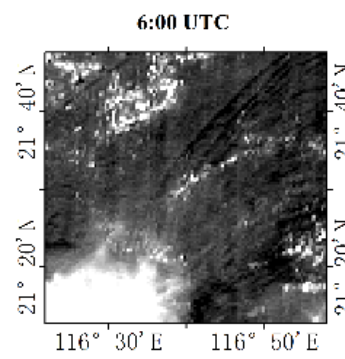

(g)

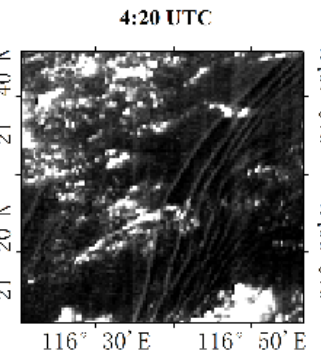

(b)

5:20 UTC

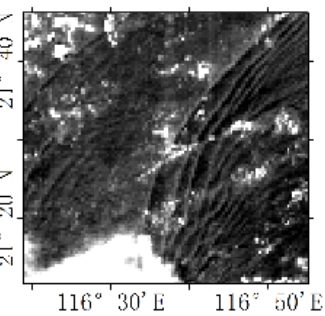

(e)

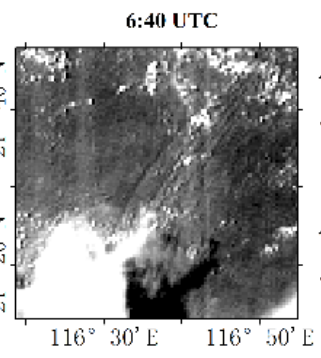

(h)

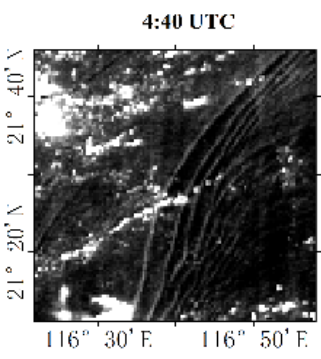

(c)

5:40 UTC

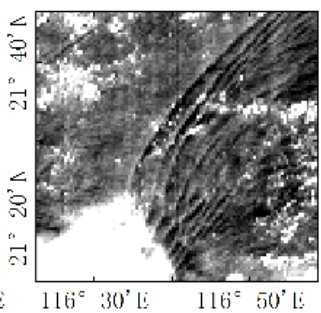

(f)

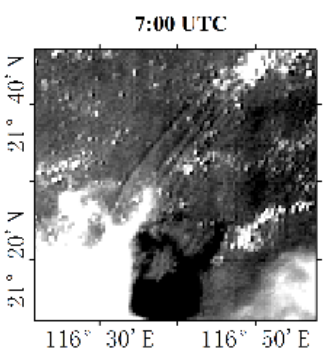

(i)

Figure 6. The time series of ISW 'b' on 30 May, 2016. Himawari-8 standard Red channel.

\subsection{The Propagation Direction of ISWs}

The propagation direction is important to estimate the ISW phase speed. Based the method introduced in section 2, the partial propagation direction of ISW 'a', ISW 'b', and ISW 'c' are extracted. The values of propagation direction angles of the three ISW packets are listed in table 1.The average propagation direction angle of ISW 'a', ISW 'b', and ISW 'c' are $293.26^{\circ}, 302.77^{\circ}$, and $298.29^{\circ}$ respectively. All ISW propagation direction angles are near $300^{\circ}$, and keep relatively stable in one single packet.

Dongsha atoll $\left(20^{\circ} 43^{\prime} \mathrm{N}, 116^{\circ} 42^{\prime} \mathrm{E}\right.$; about $25 \mathrm{~km}$ in diameter) lies on the path of the northwestward-propagating ISWs. When an ISW packet hit the Dongsha atoll, it usually, but not always, evolves into three sub-packets (Zhao et al., 2014). One subpacket propagates eastward into deep water as a result of reflection, and south and north of the atoll, two sub-packets continue propagating onto the continental shelf. In this study, the ISW ' $a$ ' is imaged before hitting the Dongsha atoll, and ISW ' $b$ ', ISW 'c' may are two packets evolved from the northwestwardpropagating impinging wave (see in Figure 2).

\begin{tabular}{|l|c|c|c|}
\hline ISW & 'a' & 'b' & 'c' \\
\hline $3: 30$ & & $293.96^{\circ}$ & \\
$3: 50$ & $300.44^{\circ}$ & & $294.94^{\circ}$ \\
$4: 10$ & $289.41^{\circ}$ & $303.93^{\circ}$ & $294.01^{\circ}$ \\
$4: 40$ & $292.67^{\circ}$ & & \\
$4: 50$ & & $303.96^{\circ}$ & \\
$5: 30$ & & $306.47^{\circ}$ & \\
$6: 10$ & & $304.09^{\circ}$ & \\
$6: 50$ & & & $305.93^{\circ}$ \\
$7: 20$ & & $304.18^{\circ}$ & \\
$8: 00$ & $290.53^{\circ}$ & & \\
Average & $293.26^{\circ}$ & $302.77^{\circ}$ & $298.29^{\circ}$ \\
azimuth & & & \\
\hline
\end{tabular}

Table 1. The propagation direction angles of three ISW cases on 30 May, 2016

\subsection{The Phase Speed of ISWs}

In this study, ISWs in the AHI images are located between $116^{\circ} \mathrm{E}$ and $118^{\circ} \mathrm{E}, 20^{\circ} \mathrm{N}$ and $22^{\circ} \mathrm{N}$. The propagation properties of three ISW trains are listed in Table 2. Figure 7 (a) (c) show the relation of ISW phase speed versus time. At 3:30 8:00 UTC, the maximum phase speed of ISW ' $a$ ' is $1.29 \mathrm{~m} / \mathrm{s}$ at $4: 20$, which is 
$0.24 \mathrm{~m} / \mathrm{s}$ faster than the minimum phase speed $(1.05 \mathrm{~m} / \mathrm{s})$ at $8: 00$. As to the ISW ' $b$ ', the speed difference between the maximum phase speed $(1.36 \mathrm{~m} / \mathrm{s})$ at $5: 30$ and minimum phase speed $(0.88$ $\mathrm{m} / \mathrm{s}$ ) at $5: 50$ is $0.48 \mathrm{~m} / \mathrm{s}$. For the ISW ' $\mathrm{c}$ ', the speed difference between maximum phase speed $(1.23 \mathrm{~m} / \mathrm{s})$ at $4: 10$ and minimum speed $(0.66 \mathrm{~m} / \mathrm{s})$ at $5: 50$ is $0.57 \mathrm{~m} / \mathrm{s}$. The root-mean-square $(\mathrm{rms})$ difference with average phase speed of ISW ' $a$ ', ISW 'c', and ISW 'c' is $0.12,0.15,0.24 \mathrm{~m} / \mathrm{s}$ respectively.

Analyze each scatter diagram, we can find the instantaneous phase speed is not a fixed value in a short time. Take the ISW ' $b$ ' for example, the center of ISW ' $b$ ' is located near $116^{\circ} 43^{\prime} \mathrm{E}$, $21^{\circ} 35^{\prime} \mathrm{N}$ and it propagates westward to shallow water, where the water depth dropped from $319 \mathrm{~m}$ to $188 \mathrm{~m}$. The water depth decreases approximately $131 \mathrm{~m}$ from the east to the west, the phase speed would keep fine declining trend over time according the relation between water depth and phase speed. However, the estimated phase speed of ISW ' $b$ ' rises and decreases over time. Due to the lack of simultaneous field measurements, we cannot validate the results, and follow-up studies are needed to address potential reasons for the variations of these ISWs.

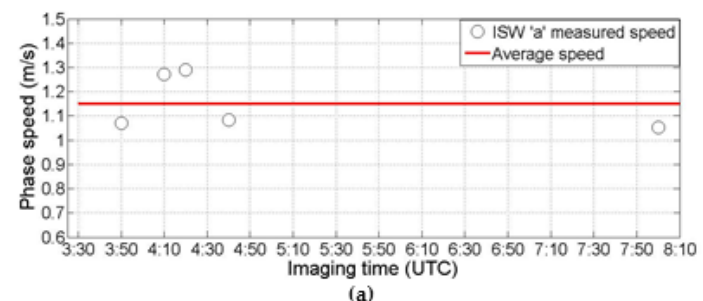

(a)

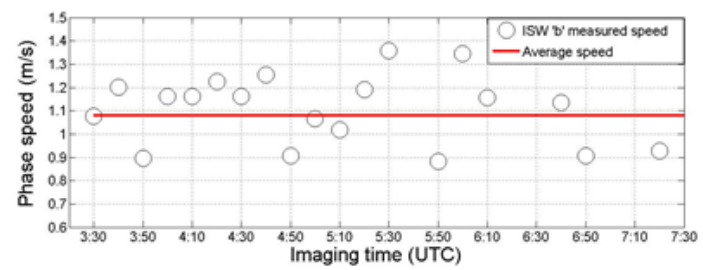

(b)

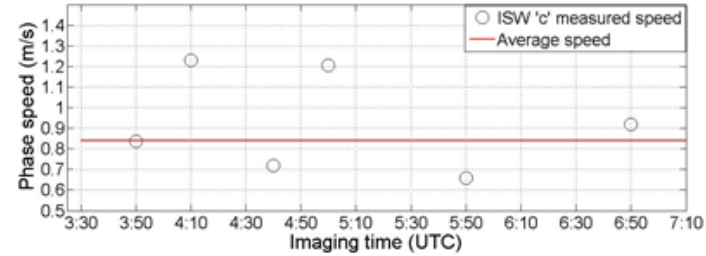

(c)

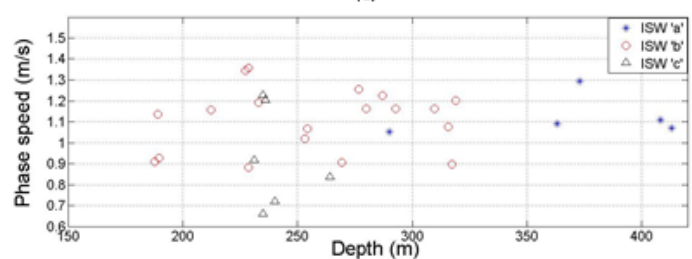

(d)

Figure 7. The scatter diagrams of ISWs phase speed and imaging time/depth.

\begin{tabular}{|l|c|c|c|}
\hline ISW & 'a' & 'b' & 'c' \\
\hline $\begin{array}{l}\text { Number of } \\
\text { wave crests } \\
\text { Bathymetry } \\
\text { range (m) }\end{array}$ & 5 & 19 & 6 \\
$\begin{array}{l}\text { Average } \\
\text { bathymetry (m) }\end{array}$ & 369.4 & 256.4 & 240.2 \\
$\begin{array}{l}\text { Average phase } \\
\text { speed (m/s) }\end{array}$ & 1.15 & 1.08 & 0.88 \\
Rms (m/s) & 0.12 & 0.15 & 0.24 \\
\hline
\end{tabular}

Table 2. The propagation properties of three ISW cases on 30 May, 2016

We used BOA-Argo monthly ocean stratification data to derive theoretical phase speeds by solving S-L equation. The results are listed in Table 3. The four Argo floats are collected from BOAArgo on May, 2016 (see in Figure 3). In the range of $240 \sim 1000$ $m$ depth, the theoretical phase speed increased from $0.92 \mathrm{~m} / \mathrm{s}$ to $1.87 \mathrm{~m} / \mathrm{s}$. The average phase speed extracted from AHI images at $230 \sim 270 \mathrm{~m}, 188 \sim 319 \mathrm{~m}$ and $290 \sim 413 \mathrm{~m}$ water depth are about $0.88,1.08,1.15 \mathrm{~m} / \mathrm{s}$ respectively (see in Figure 7(d), Table 2.).The phase speed of ISW in the SCS decreases with the shoaling bottom from east to west, both proved by the theoretical simulation and AHI images. The average water depth decreases approximately $180 \mathrm{~m}$ from the east to the west, and the corresponding phase speed decreases by about $0.27 \mathrm{~m} / \mathrm{s}$. The results demonstrate the average phase speed changes of three ISW cases are mainly caused by the changes of water depth(Liu et al., 2014a).

Argo float number 1 is near ISW ' $b$ ' and closest to three ISW case. The water depth of ISW ' $b$ ' wave crest is approximately $200 \mathrm{~m}$ after 6:50 UTC , and the derived theoretical phase speed is $0.92 \mathrm{~m} / \mathrm{s}$, the instantaneous phase speed of ISW ' $\mathrm{b}$ ' at 6:50, 7:20 UTC is $0.91 \mathrm{~m} / \mathrm{s}, 0.92 \mathrm{~m} / \mathrm{s}$, respectively(see in Figure 7 (b) and Figure 7 (d)). These can illustrate our results have good reliability.

\begin{tabular}{|l|c|c|c|}
\hline Float & Position & $\begin{array}{c}\text { Depth } \\
(\mathrm{m})\end{array}$ & $\begin{array}{c}\text { Theoreretical phase } \\
\text { speed }(\mathrm{m} / \mathrm{s})\end{array}$ \\
\hline 1 & $116^{\circ} 30^{\prime} \mathrm{N}, 21^{\circ} 30^{\prime} \mathrm{E}$ & 240 & 0.92 \\
2 & $116^{\circ} 30^{\prime} \mathrm{N}, 20^{\circ} 30^{\prime} \mathrm{E}$ & 400 & 1.20 \\
3 & $117^{\circ} 30^{\prime} \mathrm{N}, 21^{\circ} 30^{\prime} \mathrm{E}$ & 420 & 1.34 \\
4 & $117^{\circ} 30^{\prime} \mathrm{N}, 20^{\circ} 30^{\prime} \mathrm{E}$ & 1000 & 1.87 \\
\hline
\end{tabular}

Table 3. The theoretical phase speed derived from BOA-Argo on May, 2016

\section{CONCLUSIONS}

Images acquired from the AHI instrument onboard H-8 satellite are used to investigate ISWs in the SCS for the first time. The $\mathrm{H}$ 8 is a geostationary satellite, which has greatly improved the possibility of ISWs observation, compared with satellites in a polar orbit. AHI instrument can image ISWs in short time and is favorable for observing the propagation of ISWs in their lifetimes. We have demonstrated that the ISW phase speed and propagation direction can be estimated from $\mathrm{H}-8$ images, three independent 
internal wave cases including ISW ' $a$ ', ISW 'b' and ISW 'c' observed on 30 May,2016 range from 3:30 8:00 (UTC), each of them observed by AHI more than five times in the SCS. After applying image geolocation information, we can use GIS environment to extract the locations of the ISWs. In particular, the ISW phase speed can be obtained at different locations along the propagation direction. We found the ISW phase speed is not stable during its lifetime, while ISW propagation direction keeps comparatively stable during the time we have observation. The results of ISW phase speed versus time mainly influenced by water depth, the other causes including background current and ocean stratification are needed to further validation.

In this paper, we have demonstrated the new generation geostationary meteorological satellite $\mathrm{H}-8$ is a useful tool for observing and investigating ISWs in the SCS, which may be also applied in other oceans. This method can be expanded to remote sensing images from other geostationary satellite sensors, such as the Himawari-9, GOES-R, FengYun-4 (FY-4). Follow-up studies can be proceeded from following three aspects: (1) the new satellites observes numerious ISW trains in the SCS everyday while traditional polar orbit satellites are limited to revisit period. The more detailed spatial and temporal distribution features of ISWs may be discovered by analysing mas-sive case studies of ISWs in different regions, and different periods; (2) Properties of ISW propagation could extracted from AHI images. The propagation direction and phase speed are important dynamic signatures for understanding the ISW generation, propagation, and evolution. Based on these information of ISWs, we can predict the propagation path and phase speed of ISWs, so as to locate and calculate the instant location of ISW crests. The results can guide the navigation of ships and submarines, and avoid the great destructive effect of ISWs; (3) the generation processes and mechanisms of ISWs are complicated due to intricate bottom topography and various oceanic dynamics therein. For example, earth rotational effects, horizontal variation of the background currents, shear, and stratification, as well as interactions with other waves and eddies, also play an important role in the generation, propagation and dissipation of ISWs. The combination of frequent recurrence of ISWs in AHI images,field measurements and numerical simulations could lead to better understanding of ISWs.

\section{ACKNOWLEDGEMENTS}

The authors would like to acknowledge the Japanese Meteorological Agency (JMA) for use of AHI imagery associated with this research, along with the National Oceanic and Atmospheric Administration (NOAA) for their advice and support with data access and services. Argo data were collected and made freely available by the International Argo Program and the China Argo Data Center that contribute to it. (http://www.argo.org.cn;ftp://data.argo.org.cn/pub/ARGO/BOA _Argo/BOA_Argo_2016_05.nc).

\section{REFERENCES}

Alpers, W., 1985. THEORY OF RADAR IMAGING OF INTERNAL WAVES. Nature 314, 245-247.

Bai, X., Liu, Z., Li, X., Hu, J., 2014a. Generation sites of internal solitary waves in the southern Taiwan Strait revealed by MODIS true-colour image observations. International Journal of Remote Sensing 35, 4086-4098.

Bai, X.L., Liu, Z.Y., Li, X.F., Hu, J.Y., 2014b. Generation sites of internal solitary waves in the southern Taiwan Strait revealed by MODIS true-colour image observations. International Journal of Remote Sensing 35, 4086-4098.

BESSHO, K., DATE, K., HAYASHI, M., 2016. An Introduction to Himawari-8/9 Japans New-Generation Geostationary Meteorological Satellites. Meteorological Society of Japan.

Brandt, P., Romeiser, R., Rubino, A., 1999. On the determination of characteristics of the interior ocean dynamics from radar signatures of internal solitary waves. J. Geophys. Res.-Oceans 104, 30039-30045.

Chong, J., Li, F., Ouyang, Y., 2010. Simulation study on SAR imaging of internal solitary wave polarity conversion process. International Journal of Remote Sensing 31, 4887-4896.

Cox, C., Munk, W., 1954. MEASUREMENT OF THE ROUGHNESS OF THE SEA SURFACE FROM PHOTOGRAPHS OF THE SUNS GLITTER. Journal of the Optical Society of America 44, 838-850.

da Silva, J.C.B., New, A.L., Magalhaes, J.M., 2009. Internal solitary waves in the Mozambique Channel: Observations and interpretation. J. Geophys. Res.-Oceans 114, 12.

Dong, D., Yang, X.F., Li, X.F., Li, Z.W., 2016. SAR Observation of Eddy-Induced Mode-2 Internal Solitary Waves in the South China Sea. Ieee Transactions on Geoscience and Remote Sensing 54, 6674-6686.

Duda, T.F., Lynch, J.F., Irish, J.D., Beardsley, R.C., Ramp, S.R., Chiu, C.S., Tang, T.Y., Yang, Y.J., 2004. Internal tide and nonlinear internal wave behavior at the continental slope in the northern South China Sea. Ieee Journal of Oceanic Engineering $29,1105-1130$

Gagliardini, D.A., 2011. Medium Resolution Microwave, Thermal and Optical Satellite Sensors: Characterizing Coastal Environments Through the Observation of Dynamical Processes. Springer-Verlag Berlin, Berlin.

Gill, A.E., 1982. Atmosphere-Ocean Dynamics. Academic Press, San Diego, Calif 662.

Ho, C.R., Su, F.C., Kuo, N.J., Tsao, C.C., Zheng, Q., Ieee, 2009. Internal Wave Observations in the Northern South China Sea from Satellite Ocean Color Imagery, Oceans 2009 - Europe, Vols 1 and 2, pp. 1183-+.

Hong, D.B., Yang, C.S., Ouchi, K., 2015. Estimation of internal wave velocity in the shallow South China Sea using single and multiple satellite images. Remote Sensing Letters 6, 448-457. 
Hsu, M.K., Liu, A.K., Liu, C., 2000. A study of internal waves in the China Seas and Yellow Sea using SAR. Continental Shelf Research 20, 389-410.

Jackson, C., 2007. Internal wave detection using the moderate resolution Imaging spectroradiometer (MODIS). J. Geophys. Res.-Oceans 112.

Jackson, C.R., Alpers, W., 2010. The role of the critical angle in brightness reversals on sunglint images of the sea surface. J. Geophys. Res.-Oceans 115.

Kao, C.C., Lee, L.H., Tai, C.C., Wei, Y.C., 2007. Extracting the ocean surface feature of non-linear internal solitary waves in MODIS satellite images.

Letu, H., Nagao, T.M., Nakajima, T.Y., Matsumae, Y., 2014. Method for validating cloud mask obtained from satellite measurements using ground-based sky camera. Appl. Optics 53, 7523-7533.

Li Hong, L.Z., Xu Jianping, Wu Xiaofen, Sun Chaohui, Lu Shaolei, Cao Minjie., 2017. Manual of Global Ocean Argo gridded data set (BOA-Argo) (Version 2017). 25pp.

Li, X.F., Clemente-Colon, P., Friedman, K.S., 2000. Estimating oceanic mixed-layer depth from internal wave evolution observed from Radarsat-1 SAR. Johns Hopkins Apl Technical Digest 21, 130-135.

Li, X.F., Zhao, Z.X., Pichel, W.G., 2008. Internal solitary waves in the northwestern South China Sea inferred from satellite images. Geophysical Research Letters 35, 7.

Lien, R.C., Tang, T.Y., Chang, M.H., D'Asaro, E.A., 2005. Energy of nonlinear internal waves in the South China Sea. Geophysical Research Letters 32.

Liu, A.K., Chang, Y.S., Hsu, M.-K., Liang, N.K., 1998a. Evolution of nonlinear internal waves in the East and South China Seas. Journal of Geophysical Research: Oceans 103, 79958008 .

Liu, A.K., Chang, Y.S., Hsu, M.K., Liang, N.K., 1998b. Evolution of nonlinear internal waves in the East and South China Seas. J. Geophys. Res.-Oceans 103, 7995-8008.

Liu, B., Yang, H., Zhao, Z., Li, X., 2014a. Internal solitary wave propagation observed by tandem satellites. Geophysical Research Letters 41, 2077-2085.

Liu, B.Q., Yang, H., Ding, X.W., Li, X.F., 2014b. Tracking the internal waves in the South China Sea with environmental satellite sun glint images. Remote Sensing Letters 5, 609-618.

Liu, B.Q., Yang, H., Ding, X.W., Zhao, Z.X., Li, X.F., 2013. Fusion of SAR and MODIS images for oceanic internal waves tracking in the South China Sea, in: Tian, J., Ma, J. (Eds.), Mippr 2013: Remote Sensing Image Processing, Geographic Information Systems, and Other Applications.

Meng, J.M., Zhang, J., 2007. Estimating Internal Solitary Waves Propagation Velocity in South China Sea by Using Multi-Sensor Images.

Orr, M.H., Mignerey, P.C., 2003. Nonlinear internal waves in the South China Sea: Observation of the conversion of depression internal waves to elevation internal waves. J. Geophys. Res.Oceans 108.

Porter, D.L., Thompson, D.R., 1999. Continental shelf parameters inferred from SAR internal wave observations. Journal of Atmospheric and Oceanic Technology 16, 475-487.

Ramp, S.R., Tang, T.Y., Duda, T.F., Lynch, J.F., Liu, A.K., Chiu, C.S., Bahr, F.L., Kim, H.R., Yang, Y.J., 2004. Internal solitons in the northeastern South China Sea - Part I: Sources and deep water propagation. Ieee Journal of Oceanic Engineering 29, $1157-1181$

Shang, H.Z., Chen, L.F., Letu, H.S., Zhao, M., Li, S.S., Bao, S.H., 2017. Development of a daytime cloud and haze detection algorithm for Himawari-8 satellite measurements over central and eastern China. J. Geophys. Res.-Atmos. 122, 3528-3543.

Shao, H., Li, Y., Li, L., 2011. Sun glitter imaging of submarine sand waves on the Taiwan Banks: Determination of the relaxation rate of short waves. J. Geophys. Res.-Oceans 116 .

Sun, L.N., Zhang, J., Meng, J.M., 2014. Analysis of Characteristics of Spatial and Temporal Distributions of Large Amplitude Internal Waves in the South China Sea Using MODIS, in: Huang, C., Bao, Y., Zhao, S. (Eds.), Information Technology for Risk Analysis and Crisis Response, pp. 801-805.

Xue, J.S., Graber, H.C., Lund, B., Romeiser, R., 2013. Amplitudes Estimation of Large Internal Solitary Waves in the Mid-Atlantic Bight Using Synthetic Aperture Radar and Marine $\mathrm{X}$-Band Radar Images. Ieee Transactions on Geoscience and Remote Sensing 51, 3250-3258.

Yang, X.F., Li, X.F., Li, Z.W., Pichel, W., Yu, Y., Ieee, 2012. ON THE ROLE OF WIND MODULATION OF INTERNAL SOLITARY WAVE SIGNATURES IN SAR IMAGES, 2012 Ieee International Geoscience and Remote Sensing Symposium, pp. 2805-2808.

Zhang, H., Wang, M., 2010. Evaluation of sun glint models using MODIS measurements. Journal of Quantitative Spectroscopy \& Radiative Transfer 111, 492-506.

Zhao, Z., Liu, B., Li, X., 2014. Internal solitary waves in the China seas observed using satellite remote-sensing techniques: a review and perspectives. International Journal of Remote Sensing 35, 3926-3946.

Zhao, Z.X., Klemas, V., Zheng, Q.N., Yan, X.H., 2004. Remote sensing evidence for baroclinic tide origin of internal solitary waves in the northeastern South China Sea. Geophysical Research Letters 31.

Zheng, Q.N., Yuan, Y.L., Klemas, V., Yan, X.H., 2001. Theoretical expression for an ocean internal soliton synthetic aperture radar image and determination of the soliton characteristic half width. J. Geophys. Res.-Oceans 106, 3141531423. 